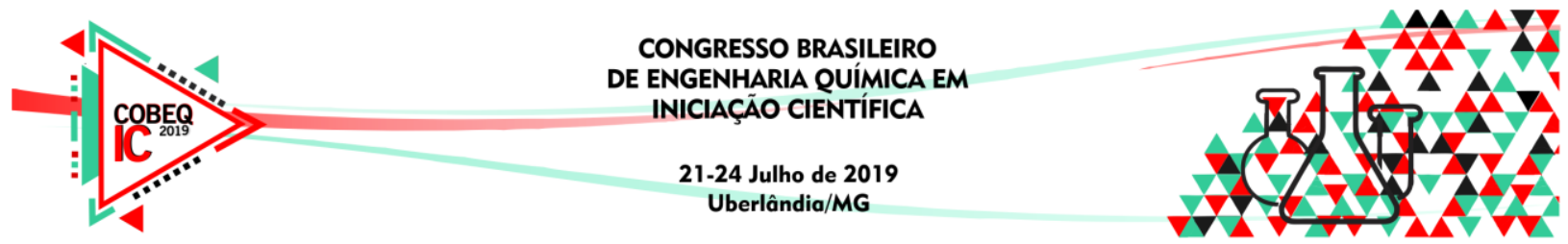

\title{
SÍNTESE DO FÁRMACO PIOGLITAZONA
}

\author{
P. A. MEIRA ${ }^{1}$, R.R.O. SILVA ${ }^{2}$ e M.S.A. PALMA ${ }^{2}$ \\ ${ }^{1}$ Faculdade de Tecnologia Termomecanica, Engenharia de Alimentos \\ ${ }^{2}$ Universidade de São Paulo, Faculdade de Ciências Farmacêuticas \\ E-mail para contato: msapalma@usp.br
}

\begin{abstract}
RESUMO - A Pioglitazona é um fármaco usado para o tratamento de diabetes mellitus tipo 2. O presente trabalho teve como objetivo a realização de três etapas da síntese do fármaco Pioglitazona. A síntese foi feita em batelada e ao final de cada etapa foram coletadas amostras que posteriormente foram analisadas em HPLC-MS. As análises comprovaram a identidade dos produtos com m/z 229,95 $(\mathrm{M}+)$ para a reação $\mathrm{I}, \mathrm{m} / \mathrm{z}$ 256,02 $(\mathrm{M}+)$ para a reação II e m/z $357.02(\mathrm{M}+)$ para a reação III.
\end{abstract}

\section{INTRODUÇÃO}

Microrreatores de fluxo contínuo são dispositivos tubulares feitos de material com resistência química e mecânica, utilizados na intensificação de processo e vêm sendo aplicados em laboratórios de pesquisa em todo o mundo devido às melhorias que proporcionam a transformações químicas. Suas pequenas dimensões internas possibilitam um grande controle das condições reacionais, as quais são difíceis de obter em reatores batelada devido à segurança do processo como, dentre outras, condições extremas de temperatura e pressão. Suas vantagens em relação aos reatores batelada são o excelente controle de troca térmica devido à alta relação superfície/volume, homogeneização mais eficiente, em razão das pequenas distâncias para difusão, levando ao aumento da velocidade da reação química, conversão, rendimento, seletividade e segurança ao se trabalhar com reagentes e produtos tóxicos e explosivos, redução da geração de resíduos e aumento da pureza do produto (TONHAUSER et al. 2012; WIRTH, 2013, PORTA et al. 2016).

A diabetes Mellitus é um distúrbio metabólico crônico caracterizado pelo excesso de glicose no sangue devido à falta de secreção de insulina, hormônio que atua como transportador da glicose do sangue para a célula (MISHRA et al. 2015; ROY et al. 2013). As complicações a longo prazo da diabetes mellitus incluem retinopatia, nefropatia e neuropatia. Além disso, ela está associada ao aumento do risco de doenças cardiovasculares (RICHTER et al. 2007).

A Pioglitazona, cuja estrutura molecular está esquematizada na Figura 1, é fármaco da classe das glitazonas, e atua como agente antihiperglicêmico de uso oral que combate a diabetes mellitus tipo 2. Sua função é reduzir os níveis de glicose no sangue, a partir da interação com o Receptor Ativado por Proliferadores de Peroxissoma gama (PPAR $\gamma$ ), receptor presente dentro do núcleo da célula que atua na resistência da insulina (PABLOSVELASCO, 2010; LI, et al. 2017). Este fármaco foi aprovado pelo Food and Drug 


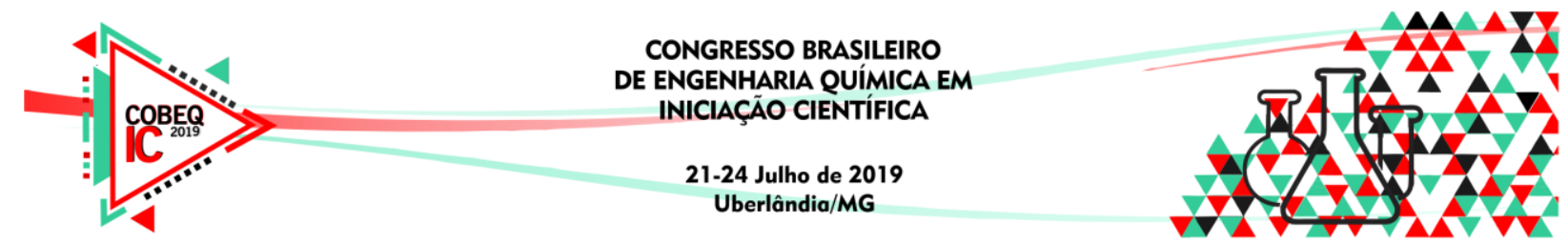

Administration (FDA) na década de 1990 e hoje é comercializado com o nome de ACTOS® (MALIK; PRASAD, 2012).

Figura 1 - Estrutura molecular da Pioglitazona (ACTOS®).<smiles>CCC1=CNC(CCOc2ccc(CC3SC(=O)NC3=O)cc2)C=C1</smiles>

Neste trabalho, foram estudadas três etapas da síntese da Pioglitazona e visa à futura transposição do processo em batelada para o processo em fluxo contínuo com o uso de microrreatores capilares.

A rota de síntese proposta para obtenção do fármaco foi adaptada de Bruno et al. (2002); Madivada et al. (2009); Menges e Balci, (2014). A Figura 2 mostra a rota de síntese da Pioglitazona.

Figura 2 - Rota de síntese da Pioglitazona.

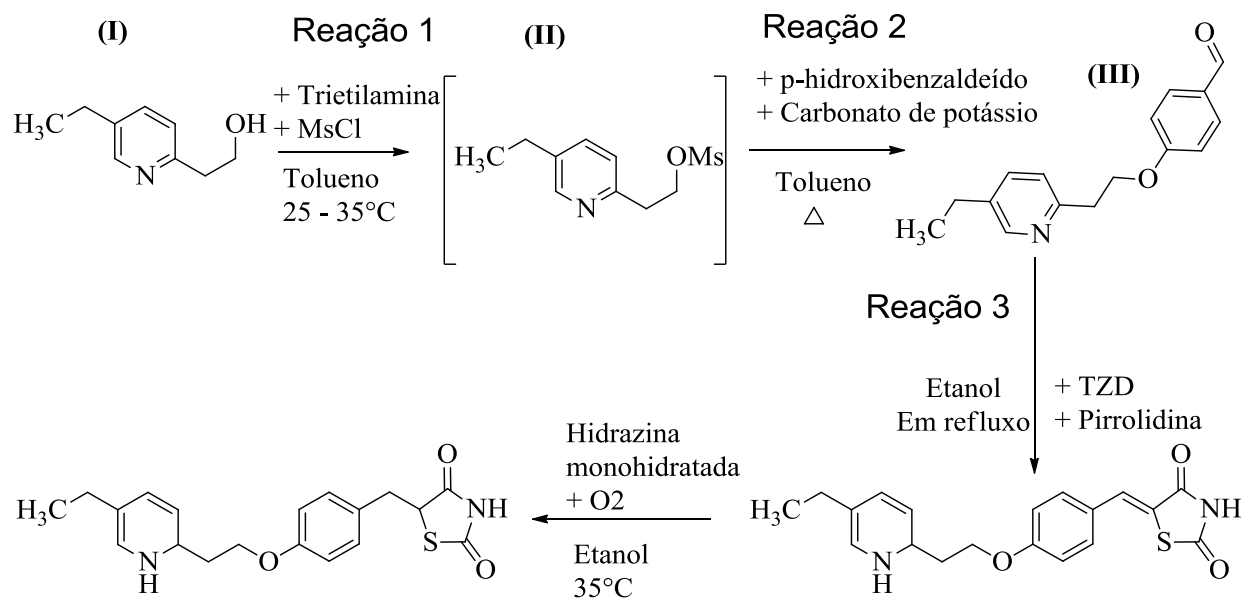

(V)

(IV)

\section{METODOLOGIA}

\subsection{Síntese em batelada}

A metodologia descrita foi adaptada de BRUNO et al. (2002) e Madivada et al. (2009).

Reação 1: 2-(5-etilpiridina-2-il)etanol (I) $(1 \mathrm{mmol})$ foi agitado com trietilamina (1,25 mmol) em tolueno $(1,8 \mathrm{~mL})$ à temperatura ambiente. Em seguida adicionou-se cloreto de 


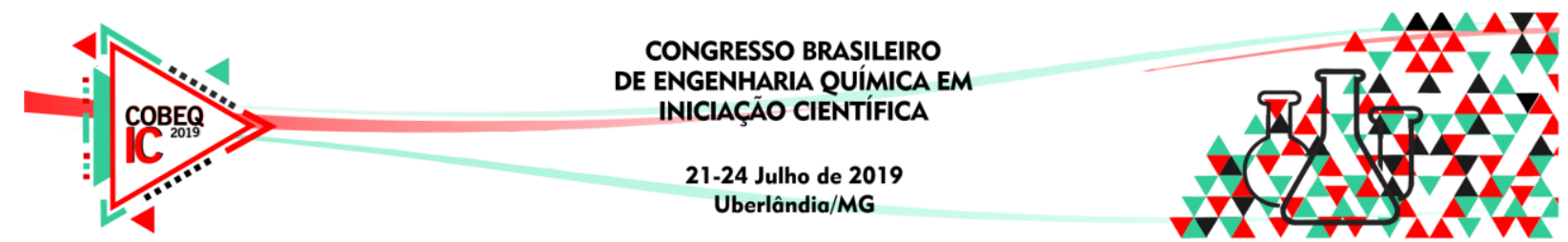

metanosulfonil $(1,12 \mathrm{mmol})$. O tempo de reação foi de $3 \mathrm{~h}$. Para a purificação do produto, foi realizada uma filtração a vácuo para retirar o sólido formado, seguida por lavagem com tolueno e solução de $4 \%$ de bicarbonato de sódio. A solução bifásica formada foi separada, sendo a fase aquosa lavada com tolueno e água. A fase orgânica contendo o intermediário II foi reservada.

Reação 2: Na fase orgânica contendo $1 \mathrm{mmol}$ do intermediário II foi adicionado phidroxibenzaldeído (1,06 mmol) e carbonato de potássio $(1,74 \mathrm{mmol})$, em $2 \mathrm{ml}$ de tolueno. Em seguida, a temperatura do meio reacional foi levada a $90^{\circ} \mathrm{C}$ e mantida sob agitação por 24h. Após o término da reação, a mistura reacional foi levada a $50^{\circ} \mathrm{C}$ e adicionou-se $20 \mathrm{~mL}$ de água destilada sob agitação. A solução bifásica formada foi separada, sendo a fase aquosa extraída com tolueno e a fase orgânica lavada com uma solução de hidróxido de sódio $5 \%$. A fase orgânica contendo o intermediário III foi reservada.

Reação 3: Adicionou-se tiazolidina-2,4-diona $(1,50 \mathrm{mmol})$ a mistura do intermediário III em $20 \mathrm{~mL}$ de tolueno. A mistura reacional foi aquecida a $100^{\circ} \mathrm{C}$ e em seguida, foi adicionado pirrolidina $(0,83 \mathrm{mmol})$ que atua como base promotora da reação. Foi mantida agitação por $4 \mathrm{~h}$. Ao final da reação, o meio reacional foi levado ao freezer para a formação de sólido e, em seguida, foi filtrado a vácuo obtendo o produto bruto IV.

\subsection{Métodos de Análise}

As amostras coletadas foram analisadas por HPLC-MS (HPLC UFLC Prominence 20AD, Shimadzu, Tokio, JP; MS Bruker Amazon Speed, fonte eletrospray, analisador ion trap, Massachussets, EUA) para identificar os produtos intermediários.

\section{RESULTADOS E DISCUSSÃO}

A identidade dos intermediários II, III e IV foi confirmada por HPLC-MS, conforme mostra as Figuras 3, 4 e 5, respectivamente. No cromatograma do intermediário II (Figura 3), foi observado apenas o $\mathrm{m} / z, 229,95\left(\mathrm{M}^{+}\right)$, inferindo que o rendimento da reação deve estar próximo a $100 \%$. Já no cromatograma do intermediário III (Figura 4), além do produto da reação com o $\mathrm{m} / \mathrm{z}$ de 256,02 $\left(\mathbf{M}^{+}\right)$, foi observado o intermediário II, reagente da reação, inferindo que o rendimento da reação deve ser inferior a $100 \%$. No cromatograma do intermediário IV (Figura 5), além do produto $\mathrm{m} / z$ 357,03 $\left(\mathbf{M}^{+}\right)$, foi observado o $\mathrm{m} / z 255\left(\mathrm{M}^{+}\right)$ e $289\left(\mathrm{M}^{+}\right)$que provavelmente corresponde a um subproduto da reação. 
Figura 3 - Espectro HPLC-MS do intermediário II

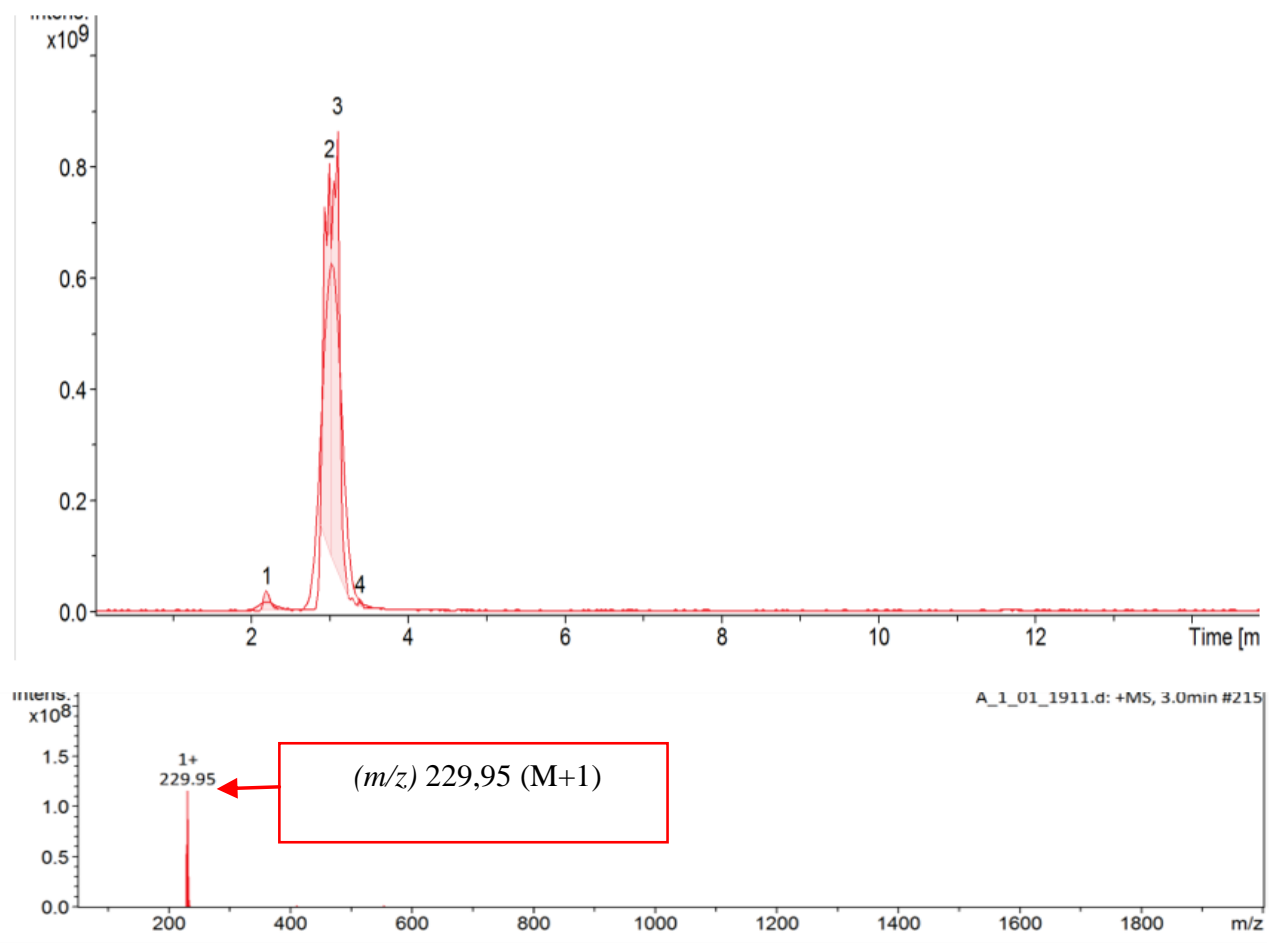

Figura 4 - Espectro HPLC-MS do intermediário III

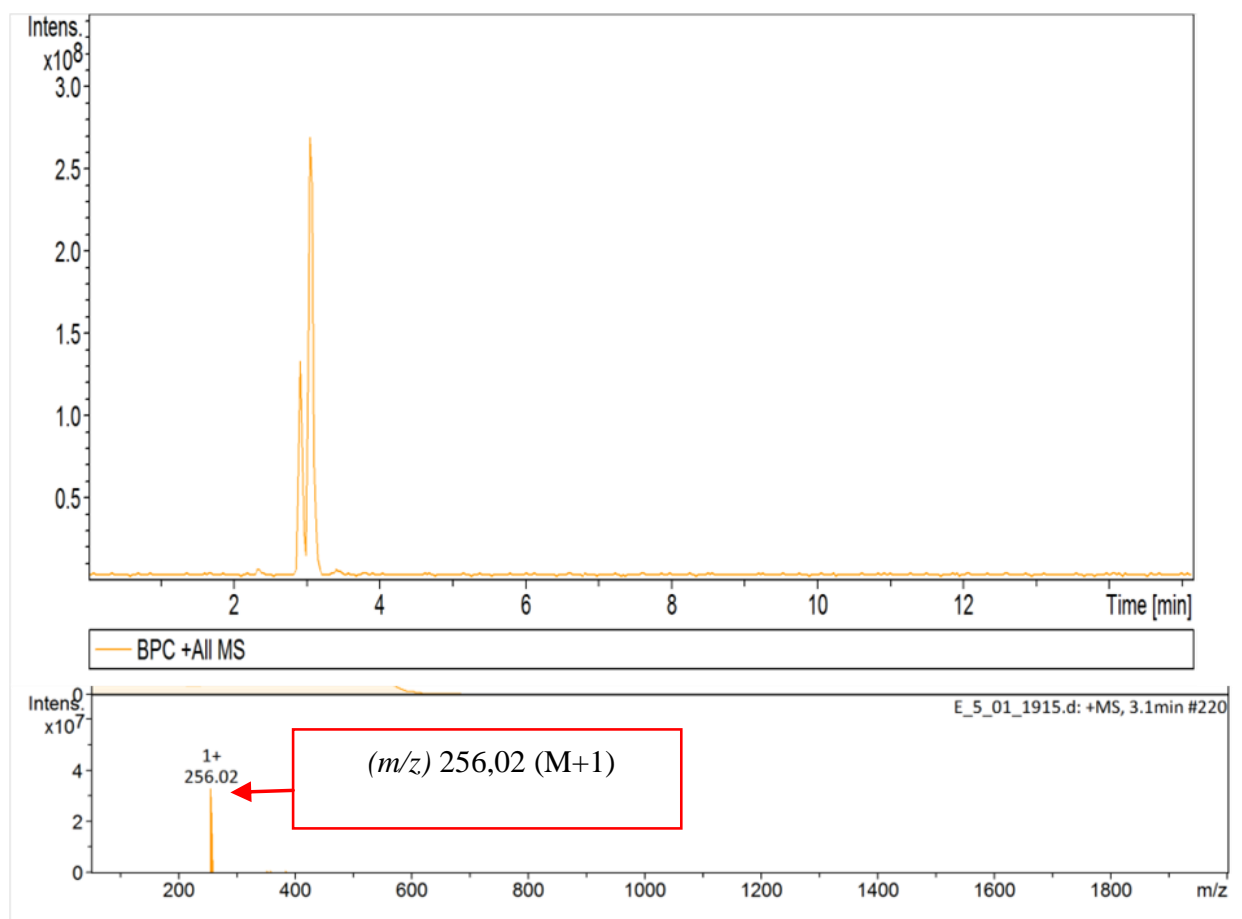




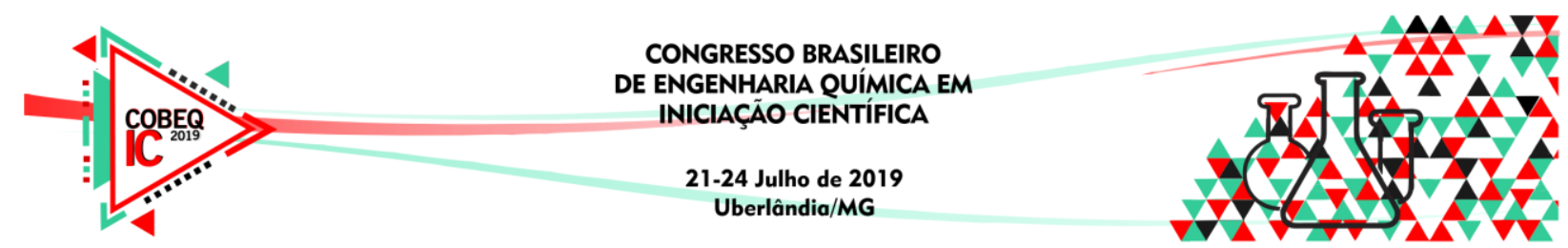

Figura 5 - Espectro HPLC-MS do intermediário IV

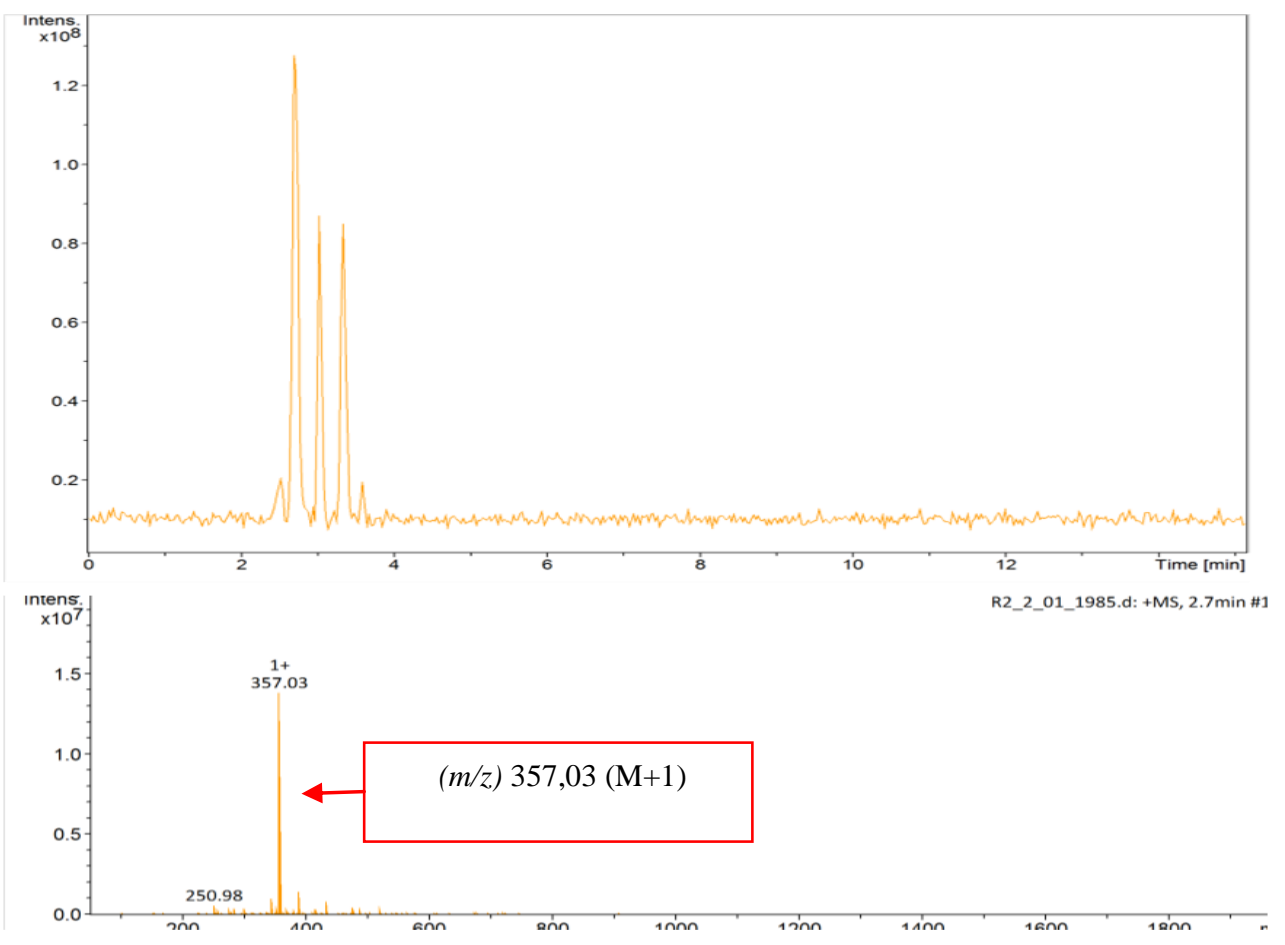

\section{CONCLUSÃO}

Foram realizadas três etapas da síntese em batelada do fármaco Pioglitazona. A caracterização do produto foi feita a partir da análise com HPLC-MS, onde foi comprovada a identidade dos intermediários com $m / z$ 229,95 $\left(\mathbf{M}^{+}\right)$para a Reação $1, m / z$ 256,02 $\left(\mathbf{M}^{+}\right)$para a Reação 2 e $\mathrm{m} / z 357.03\left(\mathrm{M}^{+}\right)$para a Reação 3. Sendo assim, verificou-se que a síntese do fármaco é possível para a metodologia testada.

Como próximas etapas serão desenvolvidos métodos para HPLC-UV para quantificar reagentes e produtos das 3 reações, otimizar o processo batelada, em termos de rendimento do produto e tempo de reação, e, posteriormente, transpor para o processo em fluxo contínuo com a utilização de microrreatores.

\section{REFERÊNCIAS}

BRUNO, G.; COSTANTINO, L.; CURINGA, C.; MACCARI, R.; MONFORTE, F.; NICOLO, F.; OTTANA, R.; VIGORITA, F. Synthesis and Aldose Reductase Inhibitory Activity of 5-Arylidene-2,4-thiazolidinediones. Bioorg. Med. Chem., v.10, p.1077-1084, 2002.

LI, X.; CHENG, C.; CONG, Y.; DU, C.; ZHAO, H. Preferential solvation of pioglitazone hydrochloride in some binary co-solvent mixtures according to the inverse KirkwoodBuff integrals method. J. Chem. Thermodyn., v.110, p.218-226. 2017. 


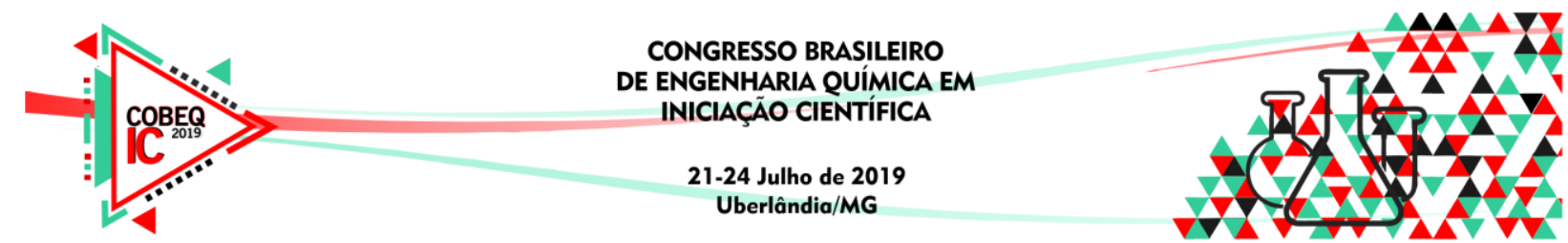

MADIVADA, L.R.; ANUMALA, R.R.; GILLA, G.; ALLA, S.; CHARAGONDLA, K.; KAGGA, M.; BHATTACHARYA, A.; BANDICHHOR, R. An Improved Process for Pioglitazone and Its Pharmaceutically Acceptable Salt. Org. Process Res. Dev., v.13, p.1190-1194. 2009.

MALIK, N.; PRASAD, D. N. Synthesis and Antimicrobial Evaluation of N-Substituted-5Benzylidene-2,4-Thiazolidinedione Derivatives. Iran J. Pharm. Res., v.8, n.3, p.209$214,2012$.

MENGES, N.; BALCI, M. Catalyst-free hydrogenation of alkenes and alkynes with hydrazine in the presence of oxygen. Synlett, v.25, n.5, p.671-676, 2014.

MISHRA, G.; SACHAN, N.; CHAWLA, P. Synthesis and Evaluation of ThiazolidinedioneCoumarin Adducts as Antidiabetic, Anti-Inflammatory and Antioxidant Agents. Lett. Journal of Organic Chemistry, v.12, n.6, p.429-445, 2015.

PABLOS-VELASCO, P. Pioglitazone: beyond glucose control. Expert Rev. Cardiovasc. Ther., v.8, n. 8, p.1057-1067. 2010.

PORTA, R.; BENAGLIA, M.; PUGLISI, A. Flow Chemistry: Recent Developments in the Synthesis of Pharmaceutical Products. Org. Process Res. Dev, v.20, n.1, p.2-25, 2016.

RICHTER, B. et al. Rosiglitazone for type 2 diabetes mellitus. Cochrane Database Syst. Rev., n.3, p.CD006063, 18 jul. 2007.

ROY, A.; DUMBARE, M. R.; PATIL, T. D.; BHANWASE, A. S.; DESHMUKH, R. D. Synthesis, Biological Evaluation and Molecular Modeling Studies of 5-[4-(substituted) benzylidene or benzyl] thiazolidine-2,4- dione with Oral Antihyperglycemic Activity. International Journal of Pharm. Tech. Research, v.53, p.1882-1895, 2013.

TONHAUSER, C.; NATALELlO, A.; LÖWE, H.; FREY, H. Micro flow Technology in Polymer Synthesis. Macromolecules, v.45, p.9551-9570, 2012.

WIRTH, T. Microreactors in Organic Chemistry Catalysis, Wiley-VCH Verlag GmbH, 2013. 